\title{
Mirabeau, Erotika Biblion
}

\section{Maurizio Melai}

\section{(2) OpenEdition}

\section{Journals}

\section{Edizione digitale}

URL: http://journals.openedition.org/studifrancesi/6658

DOI: 10.4000/studifrancesi.6658

ISSN: 2421-5856

\section{Editore}

Rosenberg \& Sellier

\section{Edizione cartacea}

Data di pubblicazione: 1 septembre 2010

Paginazione: 374

ISSN: 0039-2944

\section{Notizia bibliografica digitale}

Maurizio Melai, «Mirabeau, Erotika Biblion», Studi Francesi [Online], 161 (LIV | II) | 2010, online dal 30

novembre 2015, consultato il 08 janvier 2021. URL: http://journals.openedition.org/studifrancesi/6658 ; DOI: https://doi.org/10.4000/studifrancesi.6658

Questo documento è stato generato automaticamente il 8 janvier 2021.

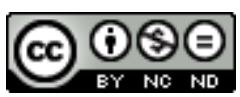

Studi Francesi è distribuita con Licenza Creative Commons Attribuzione - Non commerciale - Non opere derivate 4.0 Internazionale. 


\title{
Mirabeau, Erotika Biblion
}

\author{
Maurizio Melai
}

\section{NOTIZIA}

MIRABEAU, Erotika Biblion, édition critique avec introduction, notes et variantes par JeanPierre DUвоsт, Paris, Champion, 2009 («Libre pensée et littérature clandestine», 36), pp. 186.

1 Testo minore e troppo spesso sottovalutato di Mirabeau, Erotika Biblion è un breve trattato sulla sessualità che si inserisce nella tradizione delle opere libertine del Settecento francese. Il titolo greco-traducibile in Dell'erotismo nei libri-così come $\mathrm{i}$ titoli dei singoli capitoli che lo compongono - titoli grecizzanti quali «La tropoïde» e «L'Anandryne» o in lingua ebraica come «L'Ischia», «Kadesch»e «Behemah» - rivelano il carattere erudito e l'impostazione scientifico-enciclopedica del volume. È nel corso della sua prigionia presso il castello di Vincennes, negli anni 1777-1780, che Mirabeau, come Sade, dà sfogo alla sua ispirazione erotico-libertina; se il marchese, tuttavia, unisce la finzione romanzesca alla trattatistica erudita nella Philosophie dans le boudoir, il conte preferisce separare i due generi, componendo da una parte Ma conversion ou le libertin de qualité, dall'altra Erotika Biblion. Questa seconda opera si inscrive perfettamente nel contesto letterario della seconda metà del Settecento per numerose ragioni: per la sua natura enciclopedica, per la critica velata che essa rivolge alle istituzioni politiche ed ecclesiastiche dell'epoca, per la sua varietà di tonocontinuamente oscillante tra il serio ed il faceto-ed infine per la sua struttura composita, apparentemente priva di coesione. Il volume si presenta infatti, almeno ad una prima lettura, come un inventario dei comportamenti e dei costumi sessuali più bizzarri che hanno caratterizzato la civiltà ebraica e quella greco-romana, inventario che si profila, più in generale, come un quadro emblematico delle aberrazioni della sessualità umana. Attraverso questa documentazione eterogenea, tuttavia, emerge chiaramente un disegno unitario, ovvero quello di formulare una moderna teoria erotica e soprattutto etica, basata sul principio fondante del godimento e del piacere sensuale. Immaginando un Eden erotico primordiale, in cui tutti gli esseri viventi 
comunicavano tra loro soltanto per vie fisiche, senza dover ricorrere all'uso del linguaggio, Mirabeau interpreta l'aberrazione sessuale come una conseguenza nefasta del progressivo allontanamento umano dalla legge naturale della gioia dei sensi. Bersagli privilegiati della riflessione sottesa all'opera sono la visione tragica dell'esistenza ed il moralismo di una cultura religiosa che contrastano in modo innaturale l'affermazione di un'etica edonistica. Alla base della morale libertina che emerge dal trattato sono evidenti l'impronta dell'empirismo radicale di Mirabeau, la sua fiducia incondizionata nei sensi umani, ed ancora quel culto della volontà $e$ dell'energia che contraddistinguerà la sua attività politica. Non bisogna del resto sottovalutare le implicazioni politiche dell'epicureismo e dell'edonismo proposti dall'Erotika Biblion: l'utopia del ritorno all'Eden erotico delle origini si delinea come la raffigurazione allegorica di una società repubblicana ideale, in cui la libertà e la felicità individuali coincidano con un'armonia collettiva data dal ritrovato connubio tra sensi e spirito. È sulla base di questa possibile surdeterminazione politico-ideologica del discorso erotico che si presenta la necessità, oggi, di riscoprire e rivalutare questo testo poco conosciuto e sinora messo da parte dagli stessi biografi e commentatori dell'opera di Mirabeau.

2 La presente edizione critica di Jean-Pierre Dubost, oltre ad avere il merito di catalogare per la prima volta tutte le correzioni e le varianti testuali d'autore presenti nel manoscritto originale, ha il pregio di riportare in appendice un capitolo inedito dell'opera, intitolato «Zonáh», che si inserisce, per il suo contenuto, nella tradizione degli aneddoti su cortigiane della storia antica. Un ricco apparato di note, necessario alla comprensione di un testo così erudito e complesso, facilita inoltre la fruizione dell'opera e la rende potenzialmente accessibile ad un pubblico non soltanto di specialisti. 